\title{
Between extreme simplification and ideal optimization: antennal sensilla morphology of miniaturized Megaphragma wasps (Hymenoptera: Trichogrammatidae)
}

\author{
Anna V. Diakova ${ }^{\text {Corresp., }}{ }^{1}$, Anastasia A. Makarova ${ }^{1}$, Alexey A. Polilov ${ }^{\text {Corresp. } 1}$ \\ ${ }^{1}$ Department of Entomology, Biological faculty, Moscow State University, Moscow, Russia \\ Corresponding Authors: Anna V. Diakova, Alexey A. Polilov \\ Email address: anndiakova@yandex.ru, polilov@mail.bio.msu.ru
}

One of the major trends in the evolution of parasitoid wasps is miniaturization, which has produced the smallest known insects. Megaphragma spp. (Hymenoptera:

Trichogrammatidae) are smaller than some unicellular organisms, with an adult body length of the smallest is only $170 \mu \mathrm{m}$. Their parasitoid lifestyle depends on retention of a high level of sensory reception comparable to that in parasitoid wasps that may have antennae hundreds of times larger. Antennal sensilla of males and females of Megaphragma amalphitanum and $M$. caribea and females of the parthenogenetic $M$. mymaripenne are described, including sensillum size, external morphology, and distribution. Eight different morphological types of sensilla were discovered, two of them appearing exclusively on female antennae. Two of the types, sensilla styloconica and aporous placoid sensilla, have not been described previously. Regression analyses were performed to detect and evaluate possible miniaturization trends by comparing available data for species of larger parasitoid wasps. The number of antennal sensilla was found to decrease with the body size; M. amalphitanum males have only 39 sensilla per antenna.

The number of antennal sensilla types and sizes of the sensilla, however, show little to no correlation with the body size. Our findings on the effects of miniaturization on the antennal sensilla of Megaphragma provide material for discussion on the limits to the reduction of insect antenna. 
1

2 Between extreme simplification and ideal optimization: antennal sensilla morphology of 3 miniaturized Megaphragma wasps (Hymenoptera: Trichogrammatidae)

4

5

6 Anna V. Diakova ${ }^{1}$, Anastasia A. Makarova ${ }^{1}$, Alexey A. Polilov ${ }^{1}$

$7 \quad{ }^{1}$ Department of Entomology, Biological faculty, Moscow State University, Moscow, 119991

8 Russia

9

10 Corresponding Author:

11 Anna Diakova ${ }^{1}$

12 Leninskie gory 1-12, Moscow 119234, Russia

13 Email address: anndiakova@yandex.ru

14 
ABSTRACT

One of the major trends in the evolution of parasitoid wasps is miniaturization, which has produced the smallest known insects. Megaphragma spp. (Hymenoptera: Trichogrammatidae) are smaller than some unicellular organisms, with an adult body length of the smallest is only $170 \mu \mathrm{m}$. Their parasitoid lifestyle depends on retention of a high level of sensory reception comparable to that in parasitoid wasps that may have antennae hundreds of times larger. Antennal sensilla of males and females of Megaphragma amalphitanum and M. caribea and females of the parthenogenetic M. mymaripenne are described, including sensillum size, external morphology, and distribution. Eight different morphological types of sensilla were discovered, two of them appearing exclusively on female antennae. Two of the types, sensilla styloconica and aporous placoid sensilla, have not been described previously. Regression analyses were performed to detect and evaluate possible miniaturization trends by comparing available data for species of larger parasitoid wasps. The number of antennal sensilla was found to decrease with the body size; M. amalphitanum males have only 39 sensilla per antenna. The number of antennal sensilla types and sizes of the sensilla, however, show little to no correlation with the body size. Our findings on the effects of miniaturization on the antennal sensilla of Megaphragma provide material for discussion on the limits to the reduction of insect antenna.

\section{INTRODUCTION}

Antennae are present in all insects and perform various functions, the most obvious being perception of sensory information (Schneider, 1964). In parasitoid wasps they function to find the host habitat and location, and evaluate host's condition and suitability for oviposition (Van Baaren et al., 2007), and are involved in courtship and mating behavior (Bin et al., 1989). Parasitoid wasps antennae often have a high diversity of antennal sensilla, e.g., 14 different morphological types are found on female antenna of Trichogramma australicum Girault, 1912 (Hymenoptera: Trichogrammatidae) (Amornsak, Cribb \& Gordh, 1998). Sensilla numbers can also be exceptionally high, e.g., Microplitis croceipes (Cresson, 1872) (Hymenoptera: Braconidae individuals have about 9000 sensilla per antenna (Das et al., 2011).

One of the principal directions in parasitoid wasp evolution is miniaturization, producing such peculiar organisms as the strongly reduced male of Dicopomorpha echmepterygis Mockford, 1997 (Hymenoptera: Mymaridae), the smallest known adult insect, with a body size of 139-240 $\mu \mathrm{m}$ (Mockford, 1997). Such a decrease in body size alters their morphology, physiology, ecology and behavior (Eberhard \& Wcislo, 2011; Polilov, 2016). Their sensory organs also undergo a number of size-related adaptations. Thus, miniaturization of an eye in the smallest parasitoid wasps results in the reduction of ommatidium and rhabdom lengths and other changes in ommatidium structure (Fischer, Müller \& Meyer-Rochow, 2011; Makarova, Polilov $\&$ Fischer, 2015). Reduction in number of antennomeres and number of antennal sensilla in the smallest insect species also occurs (Polilov, 2015, 2017), and a correlation of antennae size with the body size was shown in Chalcidoidea (Symonds \& Elgar, 2013). But there have been no studies specifically on the miniaturization of antennal sensilla in parasitoid wasps

Some of the smallest parasitoid wasps belong to Megaphragma (Hymenoptera:

Trichogrammatidae); their body sizes are around $200 \mu \mathrm{m}$. Miniaturization affects them at the 
58 level of organs, cells, and even cellular structures; e.g., adults have unique anucleate neurons 59 (Polilov, 2012). While adult Megaphragma retain the complexity of internal structure, they also 60 have reductions or losses, such as absence of the heart and considerable reductions in the set of 61 muscles and tracheal system (Polilov, 2017), features common to the smallest insects. As egg62 parasitoids of the greenhouse thrips, Heliothrips haemorrhoidalis (Bouché, 1833) (Thysanoptera: kinds of behavior important for the survival of any parasitoid species, including detection of the host eggs, which are embedded under the cuticle of leaves (Bene, Gargani \& Landi, 1998), and recognition of their host at a species-specific level. Their antennae evidently remain highly functional and sensitive, despite being extremely small.

Antennal sensory structures of larger parasitoid wasps have been thoroughly studied in earlier publications. The antennal sensilla of more than 30 species of 10 different families have been investigated based on SEM photographs, with TEM studies used in some studies to discover their inner ultrastructure (Van Baaren et al., 2007). Within-species variations of sensillum sizes, numbers of sensilla, and their morphology is often described, and were thoroughly studied in Trichogramma evanescens Westwood, 1833 (Hymenoptera: Trichogrammatidae) (van der Woude \& Smid, 2016). Most of the studies treat Braconidae (Xi et al., 2010; Zhou et al., 2011) and Chalcidoidea, with special emphasis on Trichogrammatidae, Scelionidae and Platygastridae (Cave \& Gaylor, 1987; Olson \& Andow, 1993; Amornsak, Cribb \& Gordh, 1998; Isidoro, Romani \& Bin, 2001; Zhang et al., 2012). Some studies covered the biology and behavior associated with the antennal sensilla in parasitoid wasps, making it possible to predict the functions of some types of sensilla (Norton \& Vinson, 1974; Schmidt \& Smith, 1986). Despite inconsistency in terms and definitions of types of sensilla, and the shift of the focus of studies mostly to female specimens, the data obtained on the subject provides us with an opportunity to make assumptions on evolutionary trends in the antennal sensilla morphology of parasitoid wasps.

The aim of this work was to study the effects of miniaturization on the antennal sensilla of Megaphragma, and estimate the limits to the reduction of sensilla in a functional antenna.

\section{MATERIALS AND METHODS}

Material

Adult Megaphragma amalphitanum Viggiani, 1997, Megaphragma mymaripenne Timberlake, 1924 and Megaphragma caribea Delvare, 1993 were reared from eggs of $H$. haemorrhoidalis. For the study of gross morphology, specimens were fixed in alcoholic Bouin; for the study of sensilla ultrastructure, specimens were fixed in $2 \%$ glutaraldehyde (GA, EMS) solution in sodium $0.1 \mathrm{M}$ cacodylate buffer $\mathrm{pH}=7.2$ with subsequent postfixation in $1 \%$ osmium oxide (EMS) solution in the same buffer.

\section{Scanning electron microscopy}

The fixed material was gradually dehydrated through a series of ethyl alcohols (GA fixed material $-30 \%, 50 \%, 70 \%, 95 \%$ ethyl alcohol, each change for 30 minutes, $100 \%$ - two changes for 30 minutes; alcoholic Bouin fixed material - same protocol starting from the $70 \%$ ethyl alcohol step) and then acetone (100\%, two changes for 15 minutes), critical point dried (Hitachi 
101 HCP-2) and sputtered with gold (Giko IB-3). The specimens were studied and photographed

102 using Jeol JSM-6380 with a 5 megapixel digital camera and FEI Inspect F50 with a 4 megapixel

103 digital camera.

104

105

106

107

108

109

110

\section{Morphometry}

All measurements were performed on the SEM images, using measurement tool in the Fiji package of ImageJ. Normality test, descriptive statistic, ANOVA, SMA and OLS were performed using R software.

\section{RESULTS}

\section{Megaphragma amalphitanum antennae}

Antennae of M. amalphatanum are geniculate at the scape-pedicel joint (Fig.1). Male and female antennae are almost identical in shape and composition, containing the following antennomeres: scape including radicula, pedicel, and flagellum consisting of 1 ringlike anellus and three flagellomeres, the $1^{\text {st }}$ flagellomere forming the funicle and the $2^{\text {nd }}$ and $3^{\text {rd }}$ flagellomeres forming the club (sometimes this structure is also called "clava") (Fig. 2). Thus, antenna of this species is composed of five segments with two pronounced sub-segments, the radicula and anellus. The radicula forms the base of the scape and is inserted in the head via torulus, the basal socket joint upon which the radicula is articulated and which allows antennal movement in all directions. Antennal segments are elongated and cylindrical; the last flagellomere is slightly tapered. Female antennae measure $144 \pm 9 \mu \mathrm{m}$ (mean \pm sd) in length; male antennae are $136 \pm 10$ $\mu \mathrm{m}$ long (Table S1).

Morphological types of antennal sensilla and their distribution

The total number of antennal sensilla was invariable between specimens and was found to be 43 sensilla per female antenna and 39 sensilla per male antenna in all of the 25 studied specimens. We distinguished eight distinct types of sensilla on male and female antennae of $M$. amalphatanum: aporous sensilla chaetica (ChS-AP), aporous sensilla trichodea, type 1 (TS1AP), aporous sensilla trichodea, type 2 (TS2-AP), uniporous sensilla trichodea (TS-UP), sensilla styloconica (SS), multiporous placoid sensilla (MPS), sensilla basiconica (BS), and aporous placoid sensilla (PS-AP), the two latter are unique to the female antennae. The morphology, numbers and distribution of antennal sensilla was invariable within species.

133

134

Sensilla chaetica, aporous (ChS-AP)

136 These sensilla are tapered to a blunt aporous tip and inserted in a cuticular socket. Their surface is longitudinally fluted and bears no pores. They are typically protruding (Fig.3B). Three ChSAP appear on the scape, five on pedicel and one on the $1^{\text {st }}$ flagellomere in the female antenna. Overall disposition remains the same for the male specimens, except for the $1^{\text {st }}$ flagellomere, where one more sensillum was observed (Fig.2). ChS-AP are $11.5 \pm 2.62 \mu \mathrm{m}$ in length and $0.9 \pm 0.16 \mu \mathrm{m}$ in diameter in females and $9.89 \pm 2.88 \mu \mathrm{m}$ in length, $0.71 \pm 0.11 \mu \mathrm{m}$ in diameter in males (Table 1). According to the differences in sizes on different segments of the antenna, ChSAP may be further divided into subtypes. In females, chaetica sensilla on the $1^{\text {st }}$ flagellomere are significantly longer than on the pedicel and scape. By contrast, males had the longest and 
144 thickest ChS-AP on the scape, whereas difference between ChS-AP on the $1^{\text {st }}$ flagellomere and 145 pedicel was insignificant. When comparing sizes between sexes, we estimated that ChS-AP on 146 the $1^{\text {st }}$ flagellomere are significantly longer and thicker in females (Table S2).

147

148

149

150

151

152

153

154

155

156

157

158

159

160

161

162

163

164

165

166

167

168

169

170

171

172

173

174

175

176

177

178

179

180

181

182

183

184

185

186
Sensilla trichodea, aporous type 1(TS1-AP)

TS1-AP are slender, with an acute tip and a smooth surface lacking grooves and pores. They arise directly from the antenna without any kind of socket or rim, and usually are directed along its surface (Fig.4C). It is the most abundant type of sensilla in both sexes. In females, four are found on the $1^{\text {st }}$, eleven on the $2^{\text {nd }}$, and two on the $3^{\text {rd }}$ flagellomeres. Males have three TS1AP on the $1^{\text {st }}$ flagellomere and eleven on the $2^{\text {nd }}$ flagellomere; they lack TS1-AP on the $3^{\text {rd }}$ flagellomere (Fig.2). TS1-AP measure $12.7 \pm 5.42 \mu \mathrm{m}$ in length and $0.82 \pm 0.14 \mu \mathrm{m}$ in diameter in females and $7.63 \pm 1.59 \mu \mathrm{m}$ in length, $0.65 \pm 0.09 \mu \mathrm{m}$ in diameter in males (Table 1). In both sexes, the sensilla are significantly longer on each subsequent flagellomere (sensilla on the $1^{\text {st }} \mathrm{Fl} .<2^{\text {nd }}$ $\mathrm{Fl} .<3 \mathrm{~d} \mathrm{Fl}$. for females and $1^{\text {st }} \mathrm{Fl}$. $<2^{\text {nd }} \mathrm{Fl}$. for males). Females demonstrated significantly thicker and longer TS1-AP on the $1^{\text {st }}$ and $2^{\text {nd }}$ flagellomeres than males (Table S2).

Sensilla trichodea, aporous type 2 (TS2-AP)

These short, aporous sensilla are tapered, with a blunt apex, and are surrounded by a circular rim (Fig.4D). Their number and position are identical in both sexes: six TS2-AP occur in two bundles on the radicula, near the head-scape joint, and three on the pedicel, near the scapepedicel joint (Fig.2). TS2-AP are the smallest sensilla on the antenna, only $0.88 \pm 0.22 \mu \mathrm{m}$ in length and $0.55 \pm 0.14 \mu \mathrm{m}$ in diameter in females and $1.03 \pm 0.36 \mu \mathrm{m}$ in length, $0.53 \pm 0.12 \mu \mathrm{m}$ in diameter in males (Table 1). TS2-AP are significantly longer on the scape than on the pedicel, and in females also thicker, in both species. According to the intersex comparisons, females have shorter TS2-AP on the scape than males (Table S2).

Sensilla trichodea, uniporous (TS-UP)

TS-UP are long and slender, longitudinally tapered, with a slightly widened tip and an apical pore. The wall surface is smooth and lacks pores; sometimes a shallow depression can be observed at the base. TS-UP are mainly aligned with the axis of the antenna (Fig.4A). Two TSUP appear at the $2^{\text {nd }}$ flagellomere in females and three at the $3^{\text {rd }}$ flagellomere in males, protruding far below the tip of the male antenna (Fig.2). They measure $37.1 \pm 5.59 \mu \mathrm{m}$ in length and $1.36 \pm 0.23 \mu \mathrm{m}$ in diameter in females and $33.6 \pm 4.46 \mu \mathrm{m}$ in length, $1.34 \pm 0.16 \mu \mathrm{m}$ in diameter in males (Table 1). No significant size differences were found between sexes (Table S2).

Sensilla styloconica (SS)

These bulb-shaped structures have a small-elongated tip and no pores (Fig.3C). They are relatively small and there is only one of them per antenna, situated apically on the $3^{\text {rd }}$ flagellomere (Fig.2). They are significantly longer $(7 \pm 0.72 \mu \mathrm{m})$ and wider $(0.93 \pm 0.11 \mu \mathrm{m})$ in females than in males $(5.05 \pm 0.48 \mu \mathrm{m}$ length and $0.76 \pm 0.09 \mu \mathrm{m}$ width, respectively) (Tables 1 , S3).

Sensilla basiconica (BS) 
187

188

189

190

191

192

193

194

195

196

197

198

199

200

201

202

203

204

205

206

207

208

209

210

211

212

213

214

215

216

217

218

219

220

221

222

223

224

225

226

227

228

229

BS are found only in females. It is a robust structure situated apically at the tip of antenna and aligned with its axis with multiple pores on a blunt tip (Fig.3D). BS protrude beyond and below all other sensilla on the $3^{\text {rd }}$ flagellomere of the female antenna. BS are $17.1 \pm 2.04 \mu \mathrm{m}$ long and $1.96 \pm 0.19 \mu \mathrm{m}$ wide (Table 1 ).

Multiporous placoid sensilla (MPS)

The walls of these long, thick sensilla are merged with the surface of the antenna and covered with numerous pores, observable at a high magnification $(9000 \times)$ (Fig.3A). The tips of the MPS are detached from the antennal surface and have small tapered aporous protrusions. MPS are situated identically in males and females. There are two of MPS per antenna; they appear at the lateral and median surfaces of the $3^{\text {rd }}$ flagellomere, opposing each other and parallel to the longitudinal axis of the antenna (Fig.2). They are significantly longer $(37.3 \pm 3.58 \mu \mathrm{m})$ and wider $(2.62 \pm 0.27 \mu \mathrm{m})$ in females than in males $(21.9 \pm 5.61 \mu \mathrm{m}$ length and $1.82 \pm 0.38 \mu \mathrm{m}$ width, respectively) (Tables 1, S2). The detached tips measure $3.69 \pm 1.36 \mu \mathrm{m}$ in females and $3.76 \pm 4.51$ $\mu \mathrm{m}$ in males (Table 1).

\section{Placoid sensilla (PS)}

These large, conspicuous sensilla are unique to females and occur on the $3^{\text {rd }}$ flagellomere, opposing each other at its dorsal and ventral surfaces (Fig.4B). No pores were observed even at a magnification of $130000 \times$. PS are fused with the antennal surface and form large detached protrusions at the tip of antenna (Fig.2). They measure 39.9 $\pm 4.15 \mu \mathrm{m}$ in length and $2.48 \pm 0.6 \mu \mathrm{m}$ in width; the protrusions are $11.7 \pm 4.32 \mu \mathrm{m}$ long (Table 1).

\section{Megaphragma caribea antennae}

This species demonstrates fused flagellomeres in both sexes, without any visible edges between the $1^{\text {st }}$ and $2^{\text {nd }}$ flagellomeres and retaining only remnants of them between the $2^{\text {nd }}$ and $3^{\text {rd }}$ flagellomeres (Fig.5). Additionally, the pedicel of males appears to be identical to that of females. Otherwise, however, the antennae of have a similar overall shape and composition to those of M. amalphitanum (Fig.1). The male and female antennae are $120 \pm 9 \mu \mathrm{m}$ and $120 \pm 7 \mu \mathrm{m}$ long, respectively (Table S1).

Morphological types of antennal sensilla and their distribution

There are 44 sensilla on the female antenna and 49 on the male antenna (12 studied specimens). The morphological types of sensilla are identical to those in M. amalphitanum (Fig.6). No difference was observed between the two species in overall sensilla structure, presence of socket, or sensilla surface properties, such as grooves and pores. The numbers and distribution of antennal sensilla in are similar to those of M. amalphitanum, except as follows. The fused $1^{\text {st }}$ and $2^{\text {nd }}$ flagellomeres lack ChS-AP in both males and females. Females have 18 TS1-AP whereas males have 25. Both sexes have an additional SS on the distal edge of the $2^{\text {nd }}$ flagellomere (Fig.5, Fig.6). It appears that this sensillum is significantly shorter than SS on the $3^{\text {rd }}$ flagellomere in females (Table S2). The sizes of the antennal sensilla and the results of ANOVA are provided in the tables (Tables 1, S2-4). 


\section{Megaphragma mymaripenne antennae}

Since M. mymaripenne is a parthenogenetic species, the data was obtained for the females of this species only. Antennae of M. mymaripenne are identical in shape and composition to those of M. amalphitanum females (Fig.1) and are $140 \pm 9 \mu \mathrm{m}$ long (Table S1).

Morphological types of antennal sensilla and their distribution

49 sensilla were found on the antenna in M. mymaripenne (15 specimens studied). The antennal sensilla morphology and types of sensilla are identical to those of M. amalphitanum females. 22 aporous TS1-AP were found. An additional SS was seen on the distal edge of the $2^{\text {nd }}$ flagellomere, significantly longer than SS on the $3^{\text {rd }}$ flagellomere (Fig.5, Fig.6). Except for the above-mentioned differences, the overall distribution and numbers of antennal sensilla were identical to M. amalphitanum females. Sizes of M. mymaripenne antennal sensilla and the results of ANOVA are provided in the tables (Tables 1, S2-4).

\section{DISCUSSION}

\section{Antennal size and gross morphology}

The overall composition of antennae in M. amalphitanum, M. caribea and $M$. mymaripenne is typical for most groups of parasitoid hymenopterans. All three species have three flagellomeres (fused in M. caribea males and females), as in the females of several Trichogramma species (Olson \& Andow, 1993; Amornsak, Cribb \& Gordh, 1998; Consoli, Kitajima \& Parra, 1999; Zhang et al., 2012; van der Woude \& Smid, 2016). Most Trichogrammatidae and Mymaridae, and most larger parasitoid wasps in other families of parasitoid wasps have significantly more flagellar segments; e.g., Pteromalus puparum (Linnaeus, 1758) (Hymenoptera: Pteromalidae) has 12 flagellomeres, and M. croceipes and Cotesia marginiventris (Cresson, 1865) (Hymenoptera: Braconidae) have 16 flagellomeres (Das et al., 2011). The observed reduction in the number of flagellomeres is a common feature among miniaturized insects, known also in some of the smallest species of Ptiliidae and Corylophidae (Coleoptera) (Polilov, 2015).

The antennae of $M$. caribea are considerably different from those of $M$. mymaripenne and M. amalphitanum: in M. caribea flagellomeres are fused in both sexes (Fig.1C, 4A-H). In female egg parasitoids, the last flagellomeres are sometimes fused into a club (Romani, Isidoro \& Bin, 2010), e.g., in Amitus spiniferus (Brèthes, 1914) (Hymenoptera: Platygasroidea) (Isidoro, Romani \& Bin, 2001). By contrast, Ooencyrtus phongi Trjapitzin, Myartseva \& Kostjukov, 1977 (Hymenoptera: Encyrtidae), Metaphycus parasaissetiae Zhang and Huang, 2007 (Hymenoptera: Encyrtidae), Trichogramma dendrolimi Matsumura, 1926 and T. australicum Girault, 1912 (Hymenoptera: Trichogrammatidae) have a single club segment in males, which is separated into flagellomeres in females (Amornsak, Cribb \& Gordh, 1998; Xi et al., 2011; Zhang et al., 2012; Zhou et al., 2013b). In the case of $M$. caribea, both sexes have a fused club, which is uncommon. The antennal lengths of the three species are diminutive, from $120 \mu \mathrm{m}$ in $M$. caribea to 144 in M. amalphitanum females (Table S1), and minute Chalcidoidea species have antennae that are 1.5-4 times longer (Amornsak, Cribb \& Gordh, 1998; Baaren et al., 1999; Zhou et al., 2013). 
273 Interestingly, in the shortest winged insect, the parasitoid wasp Kikiki huna Huber, 2000

274 (Hymenoptera: Mymaridae) (Huber \& Noyes, 2013), antennal length is more than $151 \mu \mathrm{m}$,

275 which makes the antennae of Megaphragma possibly the smallest functional parasitoid antennae 276 ever described.

277

278

279

280

281

282

283

284

285

286

287

288

289

290

291

292

293

294

295

296

297

298

299

300

301

302

303

304

305

306

307

308

309

310

311

312

313

314

315

\section{Number of antennal sensilla}

The number of antennal sensilla significantly decreases with the body size in parasitoid wasps (Fig.7A, Table 2). T. australicum have 3-6 times as many sensilla as the studied species(Amornsak, Cribb \& Gordh, 1998), Pteromalidae species have 23 times as many as the studied species (Onagbola \& Fadamiro, 2008; Dweck, 2009), and some Braconidae species have hundreds of times as many(Gao, Luo \& Hammond, 2007; Xi et al., 2010; Das et al., 2011). The number of antennal sensilla recorded in the studied species is the smallest known among parasitoid wasps, except for the highly reduced male of Dicopomorpha echmepterygis (Hymenoptera: Mymaridae) (Mockford, 1997). Even the minute K. huna, the smallest winged insect (body length $=158-190 \mu \mathrm{m}$ ) appears to have about twice as many antennal sensilla as the species treated in our study, judging by SEM photographs (Huber \& Noyes, 2013). Thus, it is very likely that $M$. amalphitanum, M. mymaripenne and $M$. caribea are nearing the lowest number of antennal sensilla required for a highly sensitive parasitoid antenna.

The variation in number of sensilla also seems to be reduced, the smaller the species becomes. Thus, in the three species studied the numbers of antennal sensilla are completely invariable within species (sexual dimorphism being taken into account). By contrast, in larger parasitoid wasps the numbers of sensilla vary significantly within species; e.g., in O. phongi (Xi et al., 2011) the number of trichoid sensilla of type 1 is $1549 \pm 67.9$ (mean $\pm \mathrm{se}, \mathrm{n}=6$ ). Even in the tiny Trichogramma australicum, T. galloi Zucchi, 1988, T. pretiosum Riley, 1879, T. nubilae Ertle and Davis, 1974, and T. evanescens (Hymenoptera: Trichogrammatidae) the numbers of antennal sensilla significantly vary within species, and for several types of sensilla the correlation with the body size was shown (Olson \& Andow, 1993; Amornsak, Cribb \& Gordh, 1998; Consoli, Kitajima \& Parra, 1999; van der Woude \& Smid, 2016).

\section{Morphological types of antennal sensilla}

The terminology used to describe insect antennal sensilla is inconsistent and confusing. For instance, there are at least four terms describing one of the antennal sensilla types in Trichogramma (Ruschioni et al., 2012), one based on the external appearance of the sensillum ("Falcate Sensilla", Amornsak, Cribb \& Gordh, 1998, "Multiporous Pitted Sensilla Trichoid C", Olson \& Andow, 1993), another on its supposed functions ("Multiporous Gustatory Sensilla", Isidoro et al., 1996), and in one case these sensilla are designated with a letter ("Sensilla type i", Voegelé et al., 1975). In this study, we define and name sensilla types based on the morphological characteristics of sensilla as they appear when observed under a scanning electron microscope (SEM). The comparison of the terms adopted in this study with the terminology of earlier studies on parasitoid wasps is given in Table S5.

It is common for chalcidoid wasp males to have 1-3 types of sensilla fewer than females (Barlin, Vinson \& Piper, 1981; Amornsak, Cribb \& Gordh, 1998; Van Baaren et al., 1999; Xi et al., 2011; Zhang et al., 2012; Zhou et al., 2013b; Namikawa \& Amornsak, 2016), although in 
316 several cases the same number of types was reported for both sexes (Onagbola \& Fadamiro, 317 2008; Jun et al., 2013). Likely, the additional types of sensilla found in females are required for 318 the biological tasks exclusive for that sex, e.g. searching for host eggs and evaluating their suitability for parasitism. In compared to males, female M. amalphitanum and M. caribea have two more types of sensilla (BS and PS).

We found no correlation between the number of antennal sensilla types and body size in our data or when these were combined with the data on larger Chalcidoidea and Braconidae (Fig.7B, Table 2). The need for heterogeneous and varied information about the environment necessitates a diversity of receptors to detect that information, no matter what the size of the organism.

The possible functions of the sensilla in our work have been derived from morphological features, such as the overall shape of sensillum, presence and number of pores, presence of a basal socket, and position of the sensillum on the antenna (Van Baaren et al., 2007). Comparison with earlier data was based on the external morphology of sensilla as seen in SEM photographs.

Sensilla chaetica, aporous (ChS-AP)

ChS-AP are common in parasitoid wasps and have been described in almost every study on antennal sensilla. They often are the most abundant type on the antenna (Onagbola \& Fadamiro, 2008; Das et al., 2011; Xi et al., 2011; Zhou et al., 2011, 2013b; Yang et al., 2016). Their aporous walls, elongated shape, and presence of the basal socket suggest a mechanosensory function, which agrees with TEM data (Chiappini, Solinas \& Solinas, 2001).

Sensilla trichodea, aporous type 1 (TS1-AP)

These sensilla are the most abundant in the studied species. They were described in species of Trichogramma (Olson \& Andow, 1993; Amornsak, Cribb \& Gordh, 1998; Consoli, Kitajima \& Parra, 1999; Zhang et al., 2012; van der Woude \& Smid, 2016) and one species of Braconidae (Dweck, Gadallah \& Darwish, 2008). TS1-AP lack pores and a basal socket and therefore were considered in most earlier studies as protective structures without sensory function, and described as microtrichia or setiform structures rather than sensilla. However, their inner ultrastructure has not been described yet, and thus their true function remains unknown.

Sensilla trichodea, aporous type 2 (TS2-AP)

TS2-AP are typical for parasitoid wasps; they appear in functional groups at the head-scape and scape-pedicel joints and are sometimes called "hair plates" (Romani, Isidoro \& Bin, 2010). They have been shown to measure the relative position of the scape with respect to the head in Trichogramma minutum Riley, 1871 (Hymenoptera: Trichogrammatidae). When the wasp moves its antenna, these sensilla touch the surface of antennal socket, and their initial orientation is distorted (Schmidt \& Smith, 1986). Thus, these sensilla are considered proprioceptors (Onagbola \& Fadamiro, 2008; Dweck, 2009; Xi et al., 2010, 2011, Zhou et al., 2011, 2013b,a; Wang, 2013; Namikawa \& Amornsak, 2016; Yang et al., 2016). These sensilla are sometimes termed the "Böhm bristles" after Böhm, who described them in Lepidoptera (Böhm, 1911).

Sensilla trichodea, uniporous (TS-UP) 
359

360

361

362

363

364

365

366

367

368

369

370

371

372

373

374

375

376

377

378

379

380

381

382

383

384

385

386

387

388

389

390

391

392

393

394

395

396

397

398

399

400

401

These sensilla appear unique to the studied species; sensilla similar to TS-UP in shape were described in Trichogramma nubilae, T. galloi and T. pretiosum (Olson \& Andow, 1993; Consoli, Kitajima \& Parra, 1999); however, they were multiporous and lacked a small expansion with an apical pore at the tip. The absence of wall pores and a basal socket together with the presence of an apical pore suggests gustatory function for TS-UP. In males, these sensilla are the most apically protruding; they may be used in mating behavior.

Sensilla styloconica (SS)

SS were not yet reported in parasitoid wasps. However, SS are reminiscent of the frequent coeloconic sensilla, which are described as short pegs set in pits, supposedly thermo/hygroreceptors (Romani, Isidoro \& Bin, 2010). Additionally, in Anagrus atomus (Linnaeus, 1767) (Hymenoptera: Mymaridae) coeloconic sensilla have exactly the same location as in M. mymaripenne and M. caribea, i.e., one on the $2^{\text {nd }}$ flagellomere and one on the club (Chiappini, Solinas \& Solinas, 2001). In insects thermo/gygroreceptors can take different shapes, including styloconic-like sensilla (Altner \& Loftus, 1985). Thus, we propose thermoreceptive and/or hygroreceptive function for these sensilla.

Sensilla basiconica (BS)

This robust sensilum, multiporous at its tip, is unique to females in the studied species and appears apically on the club. Basiconic-shaped sensilla with the same features have been reported in Anaphes victus Huber, 1997 and Anaphes listronoti Huber, 1997 (Hymenoptera: Mymaridae), named sensilla chaetica type 2 by Baaren et al. (1999). There are two per female antenna at the distal end of the club, whereas male A. victus and A. listronoti lack BS entirely. Similar sensilla were also reported for female $A$. atomus, two per antenna, located apically on the club (Chiappini, Solinas \& Solinas, 2001). In that study, gustatory function was supposed for BS based on the TEM photographs and presence of an apical pore system. The authors proposed involvement of BS in the recognition of microhabitat, which is the host-plant tissue wounded by the ovipositor of the host. This may also be the case in the species studied by us, as their host, the thrips H. haemorrhoidalis, inserts its eggs into leaves (Bene, Gargani \& Landi, 1998). Sensilla resembling BS were also described in the Braconidae species $M$. croceipes and $C$.

marginiventris. The overall composition and multiporous tip are almost identical to BS, but these sensilla have longitudinal grooves, are not exclusively female, and are relatively abundant (Das et al., 2011). In Metaphycus parasaissetiae (Hymenoptera: Encyrtidae) basiconic-shaped sensilla also appear only at the apex of the club, but are uniporous at the tip; they are abundant, and are found in both males and females (Zhou et al., 2013b).

Multiporous placoid sensilla (MPS)

MPS are common in parasitoid wasps and have been described in Chalcidoidea and larger Braconidae as elongated sensilla fused with the antennal surface and covered with numerous pores (Van Baaren et al., 1999; Xi et al., 2010). MPS of Megaphragma species demonstrate a unique structure, the elongated projection at the tip (Fig.3A); MPS with a similar but not identical tip shape were described in Trichogramma galloi, T. pretiosum, and T. evanescens (Consoli, Kitajima \& Parra, 1999; van der Woude \& Smid, 2016). Such sensilla were shown to 
402 have olfactory function in Apis mellifera Linnaeus, 1758 (Hymenoptera: Apidae) (Lacher, 1964).

403 In parasitoid wasps they are possibly responsible for host search and host recognition in females

404 and search for sexual partner in males. Since these functions remain fulfilled in smaller

405 parasitoid wasps, while the number and sizes of MPS are considerably reduced (see

406 corresponding paragraphs of Discussion), we suppose that the innervation of MPS should be

407 denser in smaller species. The available data on MPS innervation in parasitoid wasps supports

408 this hypothesis. In larger species of Braconidae and Icheumonidae, such as Coeloides brunneri

409 Viereck, 1911 (Hymenoptera: Braconidae) and Itoplectis conquisitor (Say, 1835) (Hymenoptera:

410 Icheumonidae), MPS are innervated by 13 and 27 neurons respectively, whereas in the small

411 chalcidoids Tetrastichus hagenowii (Ratzeburg, 1852) (Hymenoptera: Eulophidae) and Torymus

412 warreni (Cockerell, 1911) (Hymenoptera: Torymidae) more than 50 neurons innervate each MPS

413 (Richerson, Borden \& Hollingdale, 1972; Borden, Chong \& Rose, 1978; Barlin \& Vinson, 1981;

414 Barlin, Vinson \& Piper, 1981).

415

416

417

418

419

420

421

422

423

424

425

426

427

428

429

430

431

432

433

434

435

436

437

438

439

440

441

442

443

444

Placoid sensilla (PS)

These large elongated sensilla lack pores or basal socket and appear to be immobile. Thus, PS are neither mechanosensors nor chemoreceptors. No such structures have been previously described in parasitoid wasps and their function is unknown. Yet they are present in females of all three studied species, which implies their importance for the biological tasks of the female in Megaphragma.

\section{Distribution}

Within each of the species studied, sensilla distribution was found to be invariable. Between the studied species, significant differences were observed only on the flagellum so the scape and pedicel are omitted in Figure 6, showing the distribution of antennal sensilla in $M$. mymaripenne and $M$. caribea, since these segments are identical in all three studied species. Terminal flagellar segments appear to be the most species-specific parts of the antenna in Chalcidoidea (Barlin, Vinson \& Piper, 1981). Constant sensilla distribution within species and constancy of interspecies differences make the distribution of antennal sensilla a reliable distinguishing trait for species identification.

\section{Sizes of antennal sensilla}

The antennal sensillum sizes vary moderately between the studied species (Tables 1, S3). It has been found that the types of sensilla which appear on several flagellomeres (such as ChS-AP, TS1-AP, TS2-AP and SS) tend to differ considerably in length and, less often, in diameter between different flagellomeres in specimens of the same species and sex (Tables S2-4). Therefore, interspecies and intersex comparisons for these types of sensilla have been made separately for each flagellomere.

Females tend to have considerably longer and wider sensilla than males in both $M$. amalphitanum and $M$. caribea (Tables S2, S3). In three comparable studies, treating Lysiphlebus fabarum (Marshall, 1986), O. phongi, and T. australicum, where measurements were provided separately for each sex (Amornsak, Cribb \& Gordh, 1998; Xi et al., 2010, 2011), no such clear tendency in size among specimens of the same species and sex was observed. In other detailed 
445 studies on the antennal sensilla of parasitoid wasps the data on the sizes of sensilla were not 446 specified between sexes for most types of sensilla.

447 In both sexes M. amalphitanum have sensilla longer than in $M$. caribea, while $M$. 448 mymaripenne tend to have medium sensillum length. Sensillum diameters are prone to vary insignificantly, especially in males (Tables S1, S2).

The data on three types of sensilla, chemoreceptors (MPS), mechanoreceptors (ChS-AP) and proprioceptors (TS2-AP) in the studied species were combined with data on larger parasitoid wasps. Possible homologues of these sensillum types in each study have been deduced from morphological traits, relative positions, and distribution of sensilla.

Only TS2-AP length and width have been found to decrease significantly with the body size (Fig.8A, B; Table 2). TS2-AP have been shown to inform parasitoid wasps on the relative position of their antenna through changes in the scapal-head angle: TS2-AP on the scape touch the socket of antenna as it moves and deviate to different degrees from their initial orientations (Schmidt \& Smith, 1986; Romani, Isidoro \& Bin, 2010). It seems that the same mechanism is implemented in the scape-pedicel joint, the second location of these sensilla. Thus, the sizes of TS2-AP should depend on the size of the antennal socket and the distance between the scape and pedicel, which decrease with the body size. Additionally, TS2-AP appear to be remarkably shorter in Megaphragma species than in larger parasitoid wasps, in which they are 4-17 times longer.

MPS length and ChS-AP shows correlation between variables and difference of slope from zero only in OLS regression analysis. Also, the regression slope values were relatively small ( 0.39 and 0.25 , respectively). Therefore, we suppose that either there is only weak correlation of these parameters with the body length, or that it is absent.

\section{Miniaturization of sense organs in parasitoid wasps}

Our results demonstrate a strong correlation between the number of antennal sensilla and the body size in parasitoid wasps. These findings are comparable to the findings on insect compound eyes, as the decrease in body size also leads to a considerable decrease in the number of ommatidia (Polilov, 2016). Thus, species of genus Megaphragma have about 30 ommatidia per eye (M. carribea $32 \pm 3$; M. mymaripenne $29 \pm 1$; M. amalphitanum $29 \pm 1$ ). Ommatidia of the minute T. evanescens have inner ultrastructure comparable to Megaphragma (Makarova, Polilov \& Fischer, 2015), however, the number of ommatidia in their eye is about 4.5 times as high (Fischer, Müller \& Meyer-Rochow, 2011).

Sense organ sensitivity in insects with moderate differences in body size is affected mostly by their lifestyles (Stöckl et al., 2016). Insects can have a 30 times difference in body size and 1000 times difference in the body volume; it seems logical to suggest that the difference in the sensitivity of their sensory organs should also be considerable though there is no definite evidence for this. While relatively reduced sensitivity might be true for vision (Palavalli-Nettimi \& Narendra, 2018), Megaphragma species seem to have a level of olfactory and gustatory sensitivity close to that of larger parasitoid wasps. This needs to be further investigated to make more accurate statements about the retention of sensitivity in a miniaturized antenna.

The miniaturization of insect sensory organs results in the reduction of the relative volume of the structures which process sensory information (Makarova \& Polilov, 2013a), e.g., the 
488 complexity of antennal sensory system was shown to correlate with the size of antennal lobes 489 and individual glomeruli (Kelber, Rössler \& Kleineidam, 2009; Mysore, Shyamala \& Rodrigues, 490 2010), while the number of ommatidia in a compound eye was shown to correlate with the size of the optic lobes (Power, 1943; Rein, Zöckler \& Heisenberg, 1999; Gronenberg \& Hölldobler, 1999). Interestingly, the decrease of the relative volume was shown to be different for each of the optic ganglia (Makarova \& Polilov, 2013b).

494

Despite a dramatic reduction in the number of antennal sensilla and number of ommatidia

495 in miniaturized parasitoid wasps, the sizes of these sense structures did not show any strict correlation with the body size. It appears that the limit of eye miniaturization is set by the diameter of one facet, which determines the power of the facet lens. The smallest facet diameter in insects was recorded in T. evanescens $(6.39 \pm 0.33 \mu \mathrm{m}$; (Fischer, Müller \& Meyer-Rochow, 499 2011), while in smaller Megaphragma it was measured as $8.1 \pm 0.3 \mu \mathrm{m}$ (Makarova, Polilov \&

500

501

502

503

504

505

506

507

508

509

510

511

512

513

514

515

516

517

518

519

520

521

522

523

524

525

526

527

528

529

530
Fischer, 2015). Antennal sensilla sizes are also mostly uncorrelated with the body size in parasitoid wasps. However, it seems that Megaphragma have larger relative sensilla diameters than most other chalcidoids (from $0.32 \mu \mathrm{m}$ (TS2-AP) to $2.6 \mu \mathrm{m}$ (TS1-AP)). It appears that sensilla and ommatidia are hard to miniaturize because of the complexity of their ultrastructure, which imposes the limits of their reduction.

\section{CONCLUSIONS}

The antennae of Megaphragma are the smallest functioning parasitoid antennae described to date. Large-scale comparative analysis of antennal sensilla of Megaphragma with antennal sensilla of larger Chalcidoidea and Ichneumonoidea demonstrated that such an extreme miniaturization resulted in a significant decrease of number of antennal sensilla, with only 39-49 antennal sensilla remaining. However, the decrease in the body size did not affect the number of antennal sensilla types. The studied species have eight types of antennal sensilla, including two (SS and PS) not described previously, while some of the larger species have only four. The individual sensilla sizes were also almost unaffected by the changed body size. A reduction of the number of functional elements in a sense organ accompanied with a minor decrease in their sizes is a common pattern in miniaturized insects. We suppose that the complexity of the inner ultrastructure of the sensilla prevents further miniaturization of antennal sensilla, with the smallest sensillum observed being only $0.48 \mu \mathrm{m}$ in length and $0.32 \mu \mathrm{m}$ in diameter. Thus, it is very likely that Megaphragma species are close to the limit of possible reduction in a functional antenna required for the parasitoid lifestyle.

Composition and shape of the antennae along with the overall number, distribution and relative position of antennal sensilla were invariable between specimens of the same sex and species. These traits may be potentially used as reliable distinguishing characters in the taxonomy of miniature parasitoid wasps.

\section{ACKNOWLEDGEMENTS}

We are grateful to Petr Petrov for helpful comments on the manuscript.

\section{REFERENCES}

Altner H., Loftus R. 1985. Ultrastructure and Function of Insect Thermo- And Hygroreceptors. 
531

532

533

534

535

536

537

538

539

540

541

542

543

544

545

546

547

548

549

550

551

552

553

554

555

556

557

558

559

560

561

562

563

564

565

566

567

568

569

570

571

572

573

574

575

576

Annual Review of Entomology 30:273-295. DOI: 10.1146/annurev.en.30.010185.001421.

Amornsak W., Cribb B., Gordh G. 1998. External morphology of antennal sensilla of Trichogramma australicum Girault (Hymenoptera: Trichogrammatidae). International Journal of Insect Morphology and Embryology 27:67-82. DOI: 10.1016/S00207322(98)00003-8.

Van Baaren J., Boivin G., Bourdais D., Roux O. 2007. Antennal sensilla of hymenopteran parasitic wasps: variations linked to host exploitation behavior. Modern Research and Educational Topics in Microscopy 1:345-352.

Van Baaren J., Boivin G., Le Lannic J., Nénon JP. 1999. Comparison of antennal sensilla of Anaphes victus and A. listronoti (Hymenoptera, Mymaridae), egg parasitoids of Curculionidae. Zoomorphology 119:1-8. DOI: 10.1007/s004350050076.

Barlin MR., Vinson SB. 1981. Multiporous plate sensilla in antennae of the Chalcidoidea (Hymenoptera). International Journal of Insect Morphology and Embryology 10:29-42. DOI: 10.1016/0020-7322(81)90011-8.

Barlin MR., Vinson SB., Piper GL. 1981. Ultrastructure of the antennal sensilla of the cockroach-egg parasitoid, Tetrastichus hagenowii (Hymenoptera : Eulophidae). Journal of Morphology 108:97-108.

Bene G Del., Gargani E., Landi S. 1998. Heliothrips haemorrhoidalis (Bouché) and Frankliniella occidentalis (Pergande)(Thysanoptera Thripidae): life cycle, harmfulness, control. Advances in Horticultural Science 12:31-37. DOI: 10.2307/42881911.

Bernardo U., Viggiani G. 2002. Biological data on Megaphragma amalphitanum Viggiani and Megaphragma mymaripenne Timberlake (Hymenoptera : Trichogrammatidae), eggparasitoid of H. haemorrhoidalis (Bouché) Thysanoptera: Thripidae) in southern Italy. Bollettino di Laboratorio Entomologia Agraria Filippo Silvestri 58:77-85.

Bin F., Colazza S., Isidoro N., Solinas M., Vinson SB. 1989. Antennal chemosensilla and glands, and their possible meaning in the reproductive behaviour of Trissolcus basalis (Woll.) (Hym.: Scelionidae). Entomologica 24:33-97. DOI: 10.15162/0425-1016/623.

Böhm L. 1911. Die antennalen Sinnesorgane der Lepidopteren. Arbeiten aus dem Zoologischen Instituten der Universität Wien und der Zoologischen Station in Triest 2:219-246.

Borden JH., Chong L., Rose A. 1978. Morphology of the elongate placoid sensillum on the antennae of Itoplectis conquisitor. Annals of the Entomological Society of America 71:223227. DOI: 10.1093/aesa/71.2.223.

Cave RD., Gaylor MJ. 1987. Antennal sensilla of male and female Telenomus reynoldsi Gordh and coker (Hymenoptera: Scelionidae). International Journal of Insect Morphology and Embryology 16:27-39.

Chiappini E., Solinas C., Solinas M. 2001. Antennal sensilla of Anagrus atomus (L.) (Hymenoptera: Mymaridae) female and their possible behavioural significance. Entomologica 35:51-76.

Consoli FL., Kitajima EW., Parra JRP. 1999. Sensilla on the antenna and ovipositor of the parasitic wasps Trichogramma galloi Zucchi and T. pretiosum Riley (Hym., Trichogrammatidae). Microscopy Research and Technique 324:313-324.

Das P., Chen L., Sharma KR., Fadamiro HY. 2011. Abundance of antennal chemosensilla in two parasitoid wasps with different degree of host specificity may explain sexual and species differences in their response to host-related volatiles. Microscopy Research and Technique 74:900-909. DOI: 10.1002/jemt.20974.

Dweck HKM. 2009. Antennal sensory receptors of Pteromalus puparum female (Hymenoptera: 
577

578

579

580

581

582

583

584

585

586

587

588

589

590

591

592

593

594

595

596

597

598

599

600

601

602

603

604

605

606

607

608

609

610

611

612

613

614

615

616

617

618

619

620

621

622

Pteromalidae), a gregarious pupal endoparasitoid of Pieris rapae. Micron 40:769-774. DOI: 10.1016/j.micron.2009.07.012.

Dweck HKM., Gadallah NS., Darwish E. 2008. Structure and sensory equipment of the ovipositor of Habrobracon hebetor (Say) (Hymenoptera : Braconidae). Micron 39:12551261. DOI: 10.1016/j.micron.2008.03.012.

Eberhard WG., Wcislo WT. 2011. Grade changes in brain-body allometry: morphological and behavioural correlates of brain size in miniature spiders, insects and other invertebrates. Advances in Insect Physiology 40:155-214. DOI: 10.1016/B978-0-12-387668-3.00004-0.

Fischer S., Müller CHG., Meyer-Rochow VB. 2011. How small can small be: The compound eye of the parasitoid wasp Trichogramma evanescens (Westwood, 1833) (Hymenoptera, Hexapoda), an insect of 0.3- to 0.4-mm total body size. Visual Neuroscience 28:295-308. DOI: $10.1017 / \mathrm{S} 0952523810000192$.

Gao Y., Luo LZ., Hammond A. 2007. Antennal morphology, structure and sensilla distribution in Microplitis pallidipes (Hymenoptera: Braconidae). Micron 38:684-693. DOI: 10.1016/j.micron.2006.09.004.

Gronenberg W., Hölldobler B. 1999. Morphologic representation of visual and antennal information in the ant brain. The Journal of comparative neurology 412:229-40.

Huber J., Noyes J. 2013. A new genus and species of fairyfly, Tinkerbella nana (Hymenoptera, Mymaridae), with comments on its sister genus Kikiki, and discussion on small size limits in arthropods. Journal of Hymenoptera Research 32:17-44. DOI: 10.3897/jhr.32.4663.

Isidoro N., Bin F., Colazza S., Vinson SB. 1996. Morphology of antennal gustatory sensilla and glands in some parasitoid Hymenoptera with hypothesis on their role in sex and host recognition. Journal of Hymenoptera Research 5:206-239.

Isidoro N., Romani R., Bin F. 2001. Antennal Multiporous Sensilla: Their gustatory features for host recognition in female parasitic wasps (Insecta, Hymenoptera : Platygastroidea). Microscopy Research and Technique 358:350-358. DOI: 10.1002/jemt.1183.

Jun L., Qiang G., ShiChou H., Lu J., GuangWen L. 2013. Types, morphologies and distributions of antennal sensilla of Quadrastichus erythrinae (Hymenptera: Eulophidae). Florida Entomologist 96:1288-1297. DOI: 10.1653/024.096.0407.

Kelber C., Rössler W., Kleineidam CJ. 2009. Phenotypic plasticity in number of glomeruli and sensory innervation of the antennal lobe in leaf-cutting ant workers (A. vollenweideri). Developmental Neurobiology 70:222-234. DOI: 10.1002/dneu.20782.

Lacher V. 1964. Elektrophysiologische untersuchungen an einzelnen rezeptoren fur geruch, kohlendioxyd, luftfeuchtigkeit und tempratur auf den antennen der arbeitsbiene und der drohne (Apis mellifica L.). Zeitschrift fur Vergleichende Physiologie 48:587-623. DOI: 10.1007/BF00333743.

Makarova AA., Polilov AA. 2013a. Peculiarities of the brain structure and ultrastructure in small insects related to miniaturization. 1. The smallest Coleoptera (Ptiliidae). Zoologicheskii Zhurnal 92:523-533 [Entomological Review 93:703-713] DOI:

10.7868/S0044513413050073.

Makarova AA., Polilov AA. 2013b. Peculiarities of the brain organization and fine structure in small insects related to miniaturization. 2. The smallest Hymenoptera (Mymaridae, Trichogrammatidae). Zoologicheskii Zhurnal 92:695-706 [Entomological Review 93:714724] DOI: 10.1134/S0013873813060055.

Makarova A., Polilov A., Fischer S. 2015. Comparative morphological analysis of compound eye miniaturization in minute hymenoptera. Arthropod Structure and Development 44:21- 
623

624

625

626

627

628

629

630

631

632

633

634

635

636

637

638

639

640

641

642

643

644

645

646

647

648

649

650

651

652

653

654

655

656

657

658

659

660

661

662

663

664

665

666

667

668

32. DOI: 10.1016/j.asd.2014.11.001.

Mockford EL. 1997. A new species of Dicopomorpha (Hymenoptera: Mymaridae) with diminutive, apterous males. Annals of the Entomological Society of America 90:115-120. DOI: 10.1093/aesa/90.2.115.

Mysore K., Shyamala B V., Rodrigues V. 2010. Morphological and developmental analysis of peripheral antennal chemosensory sensilla and central olfactory glomeruli in worker castes of Camponotus compressus (Fabricius, 1787). Arthropod Structure and Development 39:310-321. DOI: 10.1016/j.asd.2010.04.003.

Namikawa SK., Amornsak W. 2016. Antennal sensilla morphology of Theocolax elegans (Westwood) (Hymenoptera : Pteromalidae), a larval parasitoid of the maize weevil, Sitophilus zeamais (Motschulsky) (Coleoptera : Curculionidae). Agriculture and Natural Resources 50:374-379. DOI: 10.1016/j.anres.2015.12.003.

Norton WN., Vinson SB. 1974. A comparative ultrastructural and behavioral study of the antennal sensory sensilla of the parasitoid Cardiochiles nigriceps (Hymenoptera: Braconidae). Journal of Morphology 142:329-349. DOI: 10.1002/jmor.1051420308.

Olson DM., Andow DA. 1993. Antennal sensilla of female Trichogramma nubilale (Ertle and Davis) (Hymenoptera : Trichogrammatidae) and comparisons with other parasitic Hymenoptera. International Journal of Insect Morphology and Embryology 22:507-520. DOI: 10.1016/0020-7322(93)90037-2.

Onagbola EO., Fadamiro HY. 2008. Scanning electron microscopy studies of antennal sensilla of Pteromalus cerealellae (Hymenoptera: Pteromalidae). Micron 39:526-535. DOI: 10.1016/j.micron.2007.08.001.

Palavalli-Nettimi R., Narendra A. 2018. Miniaturisation decreases visual navigational competence in ants. The Journal of Experimental Biology 221:jeb177238. DOI: 10.1242/jeb.177238.

Polilov AA. 2012. The smallest insects evolve anucleate neurons. Arthropod Structure and Development 41:29-34. DOI: 10.1016/j.asd.2011.09.001.

Polilov AA. 2015. Small is beautiful: features of the smallest insects and limits to miniaturization. Annual Review of Entomology 60:103-121. DOI: 10.1146/annurev-ento010814-020924.

Polilov AA. 2016. At the Size Limit - Effects of Miniaturization in Insects. DOI: 10.1007/978-3319-39499-2.

Polilov AA. 2017. Anatomy of adult Megaphragma (Hymenoptera: Trichogrammatidae), one of the smallest insects, and new insight into insect miniaturization. PLOS ONE 12. DOI: 10.1371/journal.pone. 0175566 .

Power ME. 1943. The effect of reduction in numbers of ommatidia upon the brain of Drosophila melanogaster. Journal of Experimental Zoology 94:33-71. DOI: 10.1002/jez.1400940103.

Rein K., Zöckler M., Heisenberg M. 1999. A quantitative three-dimensional model of the Drosophila optic lobes. Current biology 9:93-6. DOI: 10.1016/S0960-9822(99)80021-9.

Richerson J V., Borden JH., Hollingdale J. 1972. Morphology of a unique sensillum placodeum on the antennae of Coeloides brunneri (Hymenoptera: Braconidae). Canadian Journal of Zoology 50:909-913. DOI: 10.1139/z72-123.

Romani R., Isidoro N., Bin F. 2010. Antennal Structures Used in Communication by Egg Parasitoids. DOI: 10.1007/978-1-4020-9110-0.

Ruschioni S., Romani R., Riolo P., Isidoro N. 2012. Morphology and distribution of antennal multiporous gustatory sensilla related to host recognition in some Trichogramma spp. 
669

670

671

672

673

674

675

676

677

678

679

680

681

682

683

684

685

686

687

688

689

690

691

692

693

694

695

696

697

698

699

700

701

702

703

704

705

706

707

708

709

710

711

712

713

714

Bulletin of Insectology 65:171-176. DOI: 10.1111/j.1548-1492.2011.01142.x.319.

Schmidt JM., Smith JJB. 1986. Correlations between body angles and substrate curvature in the parasitoid wasp Trichogramma minutum: a possible mechanism of host radius measurement. Journal of Experimental Biology 125:271-285.

Schneider D. 1964. Insect antennae. Annual Review of Entomology 9:103-122. DOI: 10.1146/annurev.en.09.010164.000535.

Stöckl A., Heinze S., Charalabidis A., El Jundi B., Warrant E., Kelber A. 2016. Differential investment in visual and olfactory brain areas reflects behavioural choices in hawk moths. Scientific Reports 6:1-10. DOI: 10.1038/srep26041.

Symonds MRE., Elgar MA. 2013. The evolution of body size, antennal size and host use in parasitoid wasps (Hymenoptera: Chalcidoidea): a phylogenetic comparative analysis. PLoS ONE 8:e78297. DOI: 10.1371/journal.pone.0078297.

Voegelé J., Cals-Usciati J., Pihan JP., Daumal J. 1975. Structure de l'antenne femelle des trichogrammes. Entomophaga 20:161-169. DOI: 10.1007/BF02371656.

Wang Z. 2013. Morphology and ultrastructure of antennal sensilla of Macrocentrus cingulum Brischke (Hymenoptera: Braconidae) and their probable functions. Micron. DOI: 10.1016/j.micron.2013.04.003.

van der Woude E., Smid HM. 2016. How to escape from haller's rule: Olfactory system complexity in small and large Trichogramma evanescens parasitic wasps. Journal of Comparative Neurology 524:1876-1891. DOI: 10.1002/cne.23927.

Xi YQ., Yin XM., Li HJ., Zhu CD., Zhang YZ. 2010. Scanning electron microscopy studies of antennal sensilla of Lysiphlebus fabarum (Marshall) (Hymenoptera: Braconidae). Acta Entomologica Sinica 53:936-942.

Xi YQ., Yin XM., Zhu CD., Guerrieri E., Zhang YZ. 2011. Scanning electron microscopy studies of antennal sensilla of Ooencyrtus phongi (Hymenoptera: Encyrtidae). Microscopy Research and Technique 74:936-945. DOI: 10.1002/jemt.20979.

Yang SY., Zhong YZ., Zhang JP., Wang XP., Zhang F. 2016. A comparative scanning electron microscopy study on antennal sensilla of Trissolcus japonicus and Trissolcus plautiae, egg parasitoids of stink bugs (Pentatomidae). Annals of the Entomological Society of America 109:112-120. DOI: 10.1093/aesa/sav104.

Zhang S., Zhang Z., Kong X., Wang H., Zhou G., Yu J. 2012. External morphology of Trichogramma dendrolimi Matsumura (Hymenoptera: Trichogrammatidae) organ and ultrastructure of the sensilla. Microscopy Research and Technique 75:1513-1521. DOI: 10.1002/jemt.22094.

Zhou H., Wu WJ., Niu LM., Fu YG. 2013a. Antennal sensilla of female Encarsia guadeloupae Viggiani (Hymenoptera: Aphelinidae), a nymphal parasitoid of the spiraling whitefly Aleurodicus dispersus (Hemiptera: Aleyrodidae). Micron 44:365-372. DOI: 10.1016/j.micron.2012.09.001.

Zhou H., Wu WJ., Zhang FP., Fu YG. 2013b. Scanning electron microscopy studies of the antennal sensilla of Metaphycus parasaissetiae Zhang \& Huang (Hymenoptera: Encyrtidae). Neotropical Entomology 42:278-287. DOI: 10.1007/s13744-013-0113-9.

Zhou H., Wu WJ., Zhnag ZF., Zhnag Y. 2011. Antennal sensilla of Apanteles cypris Nixon (Hymenoptera: Braconidae), a larval endoparasitoid of Cnaphalocrocis medinalis Guenee (Lepidoptera: Pyralidae). Microscopy Research and Technique 74:1199-1208. DOI: 10.1002/jemt.21016. 


\section{Figure 1}

Female antennae of Megaphragma amalphitanum (A), M. mymaripenne (B) and $M$. caribea (C) (SEM, lateral view).

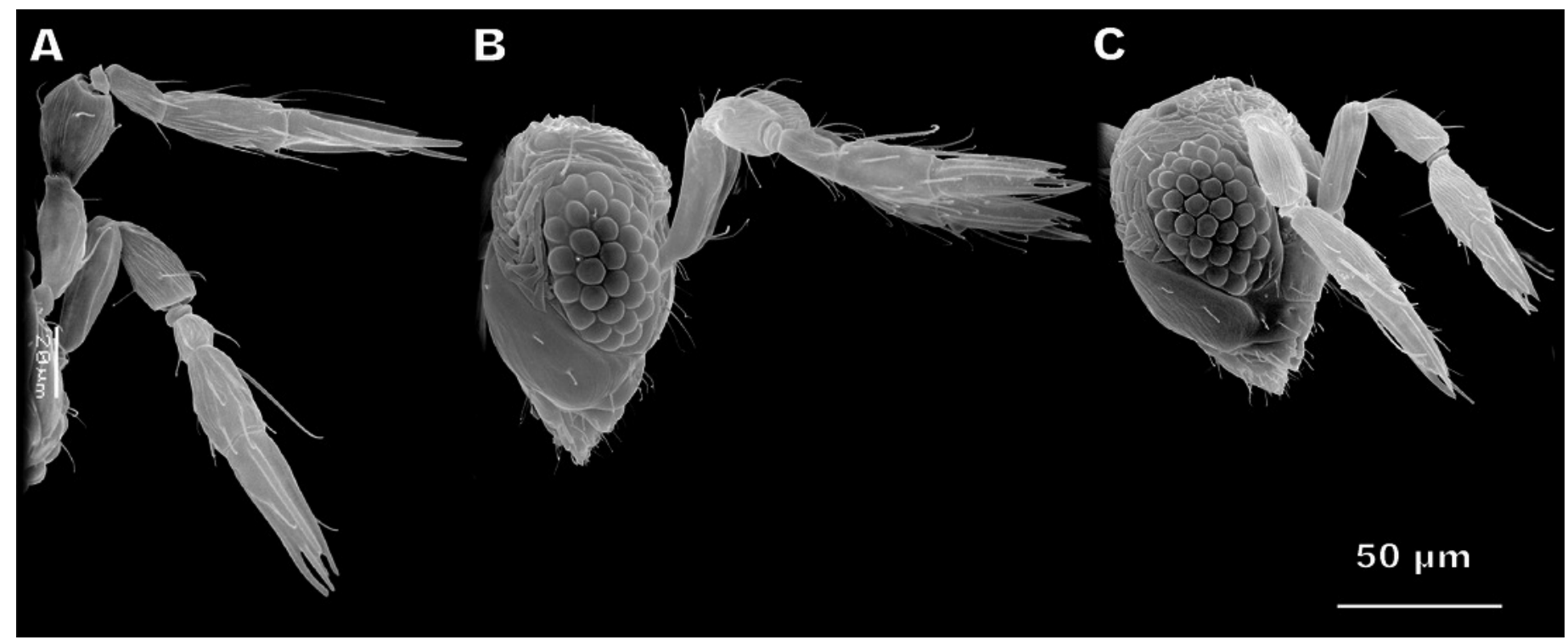




\section{Figure 2 (on next page)}

Distribution of antennal sensilla in Megaphrgama amalphitanum.

Antennae are unnaturally straightened in this figure; for their natural shape, see Fig.2. (A) female, medial view; (B) female, dorsal view; (C) female, lateral view; (D) female, ventral view; $(E)$ male, medial view; $(F)$ male, dorsal view; $(G)$ male, lateral view; $(H)$ male, ventral view. $\mathrm{Sc}=$ scape, $\mathrm{rad}=$ radicula, $\mathrm{pd}=$ pedicel, an $=$ anellus, $\mathrm{fl} 1=1^{\text {st }}$ flagellomere, $\mathrm{fl} 2=2^{\text {nd }}$ flagellomere, $\mathrm{fl} 3=3^{\text {rd }}$ flagellomere. 


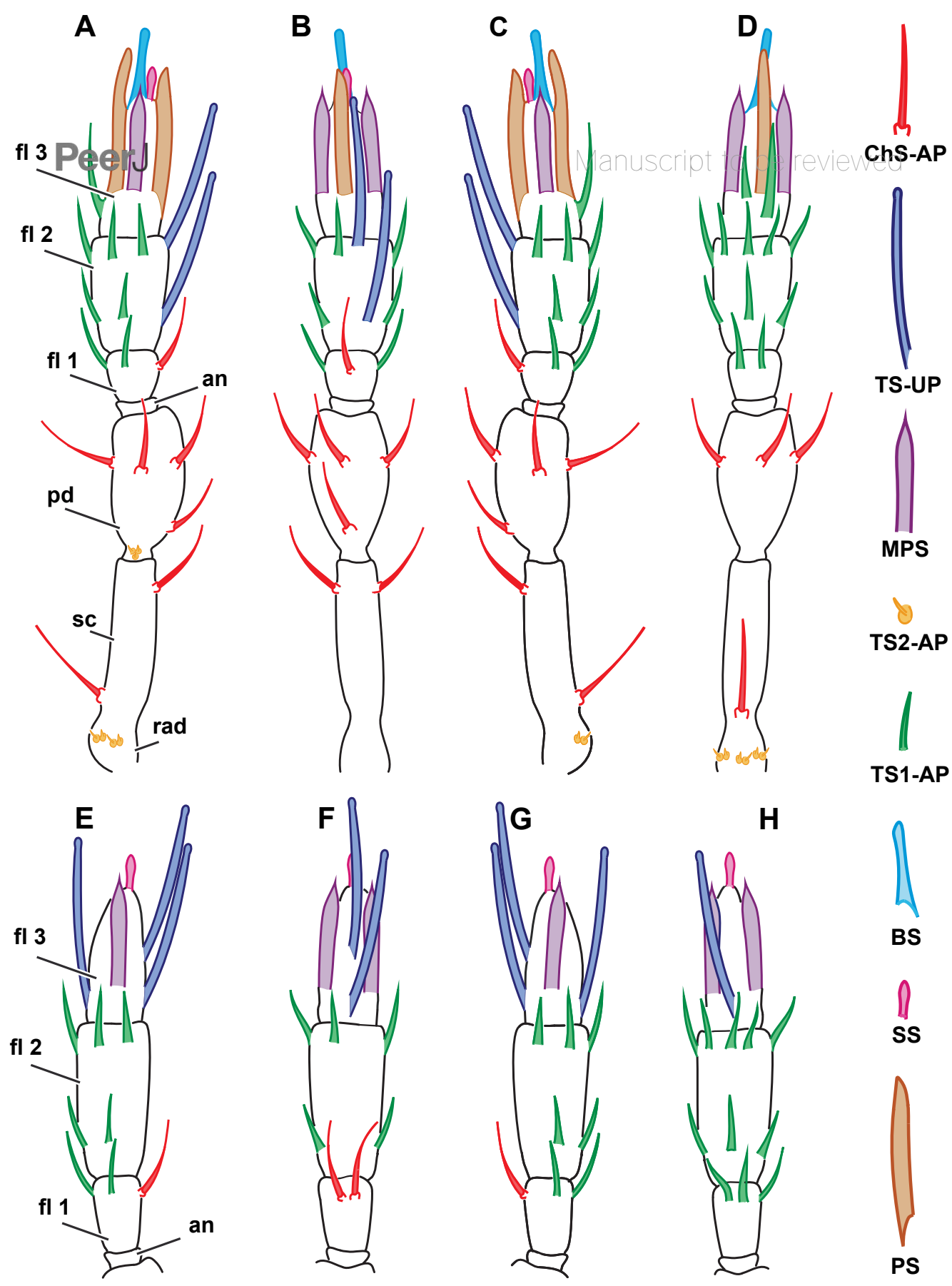




\section{Figure 3}

Morphological types of antennal sensilla in Megaphragma amalphitanum (SEM).

(A) Female club, demonstrating PS, MPS with an elongated tip and TS-UP with a widened uniporous tip. Pores on the MPS wall can be seen on a close-up. (B) ChS-AP with a socket and a fluted wall and a close-up of its aporous tip. (C) Sole SS situated on the apex of antenna with aporous tip. (D) Sole BS, unique to females, multiple tip pores are observed on a closeup.

*Note: Auto Gamma Correction was used for the image. This only affects the reviewing manuscript. See original source image if needed for review. 


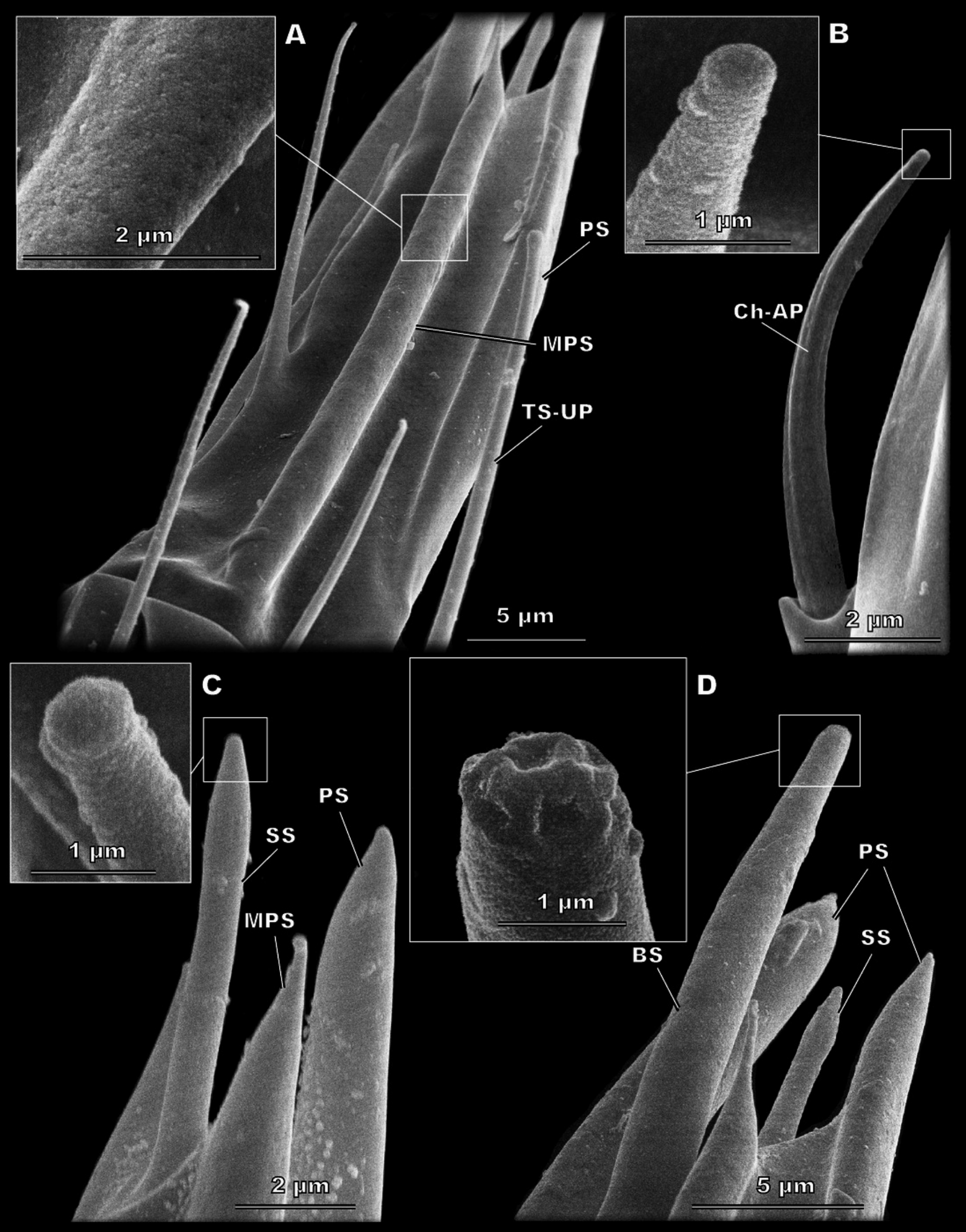




\section{Figure 4}

Morphological types of antennal sensilla in Megaphragma amalphitanum (SEM) (continuation).

(A) Male club with two MPS (one is situated on the other side of antennomere), sole SS and three TS-UP. The widened, uniporous tip of TS-UP can be seen on a close-up. (B) Female club, lateral view, demonstrating MPS, TS-UP, SS, PS and BS, two latter unique to females. Closeups of PS demonstrate absence of pores on its tip and wall. (C) TS1-AP with aporous wall and tip. (D) TS2-AP with a close-up of its aporous tip.

*Note: Auto Gamma Correction was used for the image. This only affects the reviewing manuscript. See original source image if needed for review. 


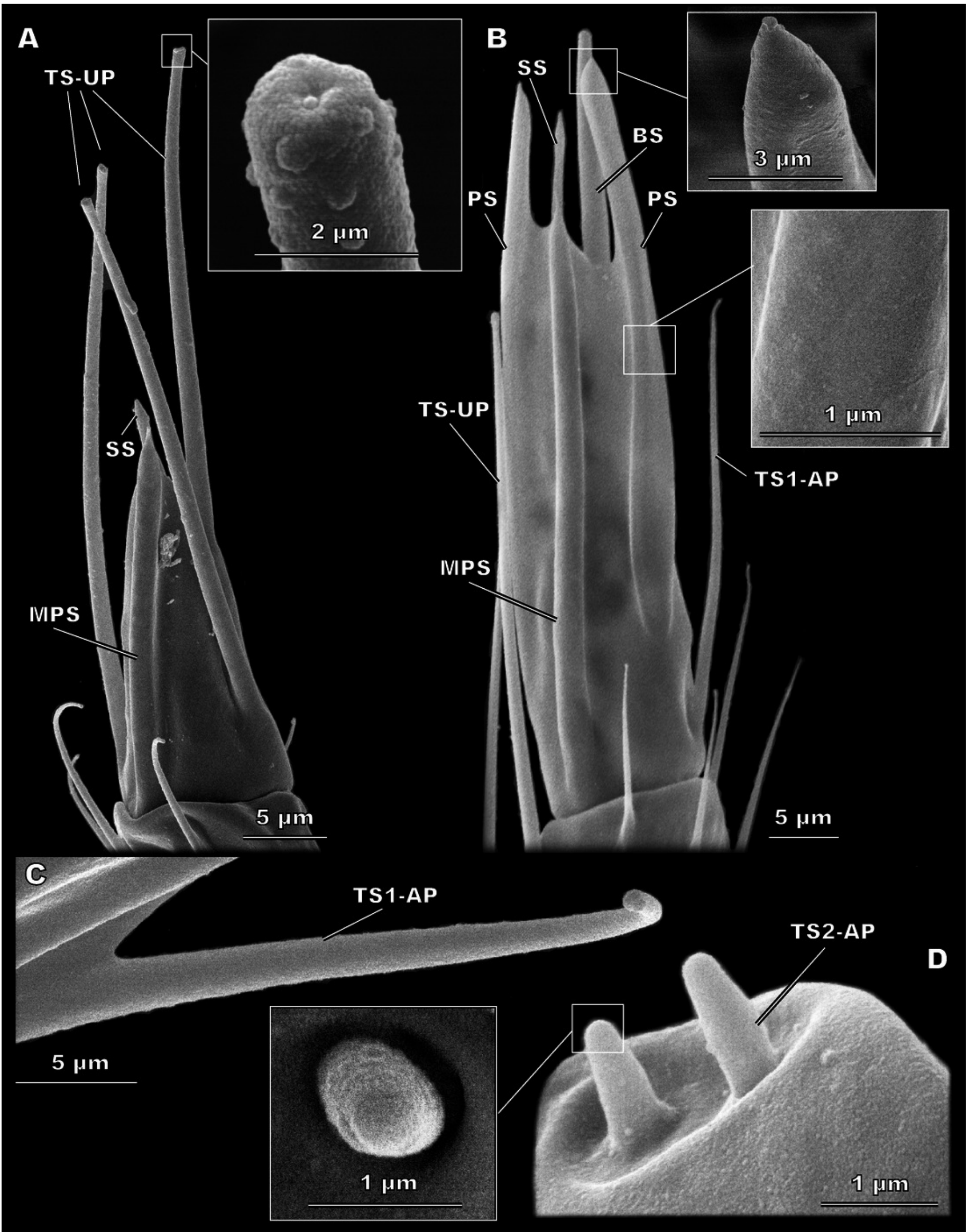




\section{Figure 5}

Detailed view of the antenna of Megaphragma caribea and M. mymaripenne (SEM).

(A) Male M. caribea fused flagellum demonstrating numerous TS1-AP, MPS, TS-UP and two SS.

(B) Female M. caribea antenna with three fused flagellomeres. (C) Female M. mymaripenne antenna. (D) Tip of M. mymaripenne antenna.

*Note: Auto Gamma Correction was used for the image. This only affects the reviewing manuscript. See original source image if needed for review. 


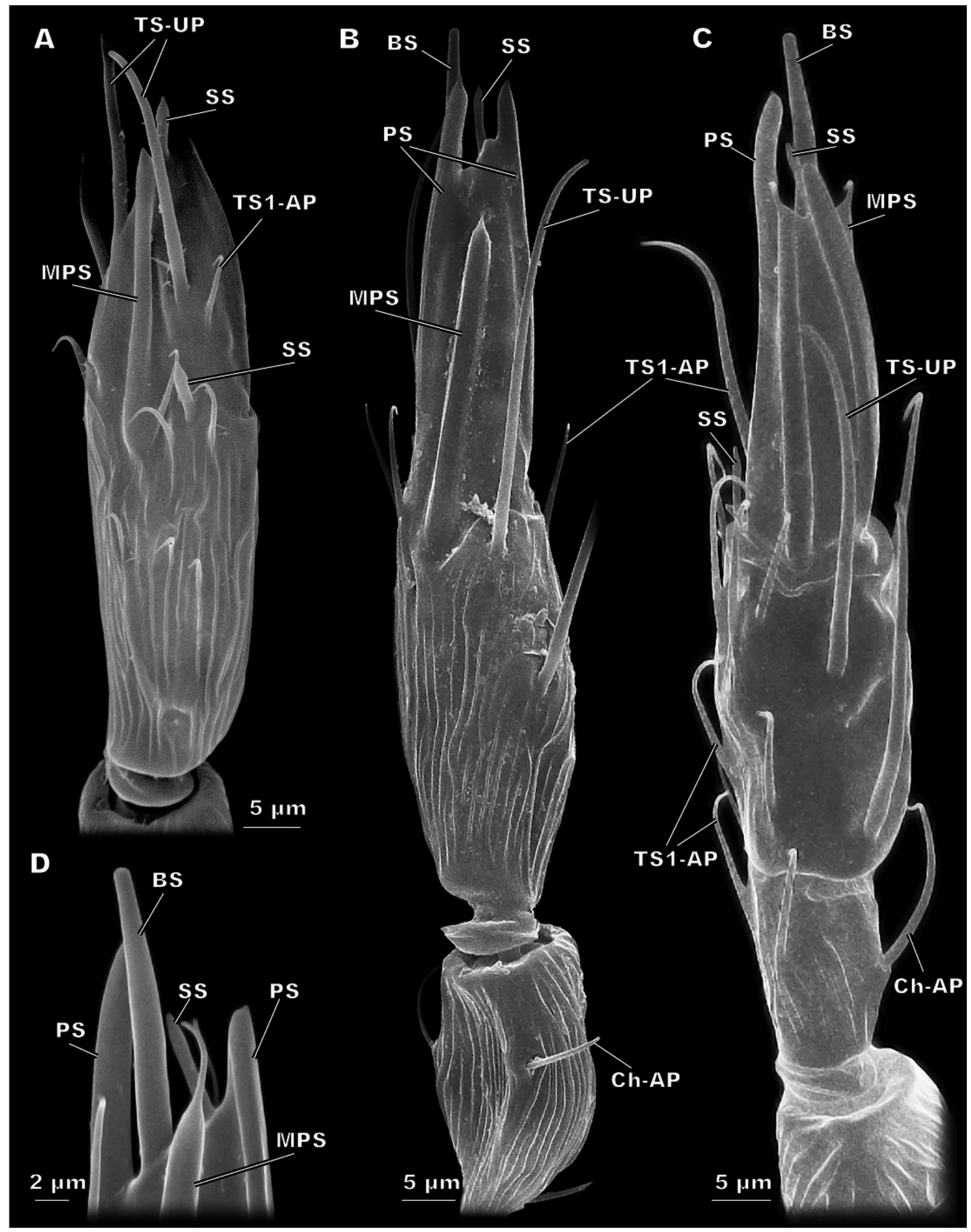




\section{Figure 6 (on next page)}

Distribution of antennal sensilla in Megaphragma caribea and M. mymaripenne.

(A) female M. caribea, medial view; (B) female M. caribea, dorsal view; (C) female M. caribea, lateral view; (D) female M. caribea, ventral view; (E) male M. caribea, medial view; (F) male M. caribea, dorsal view; (G) male M. caribea, lateral view; (H) male M. caribea, ventral view;

(I) female M. mymaripenne, medial view; (G) female M. mymaripenne, dorsal view; (K) female M. mymaripenne, lateral view; $(\mathrm{L})$ female M. mymaripenne, ventral view. $A n=$ anelli, $\mathrm{fl} 1=1^{\text {st }}$ flagellomere, $\mathrm{fl} 2=2^{\text {nd }}$ flagellomere, $\mathrm{fl} 3=3^{\text {rd }}$ flagellomere. 


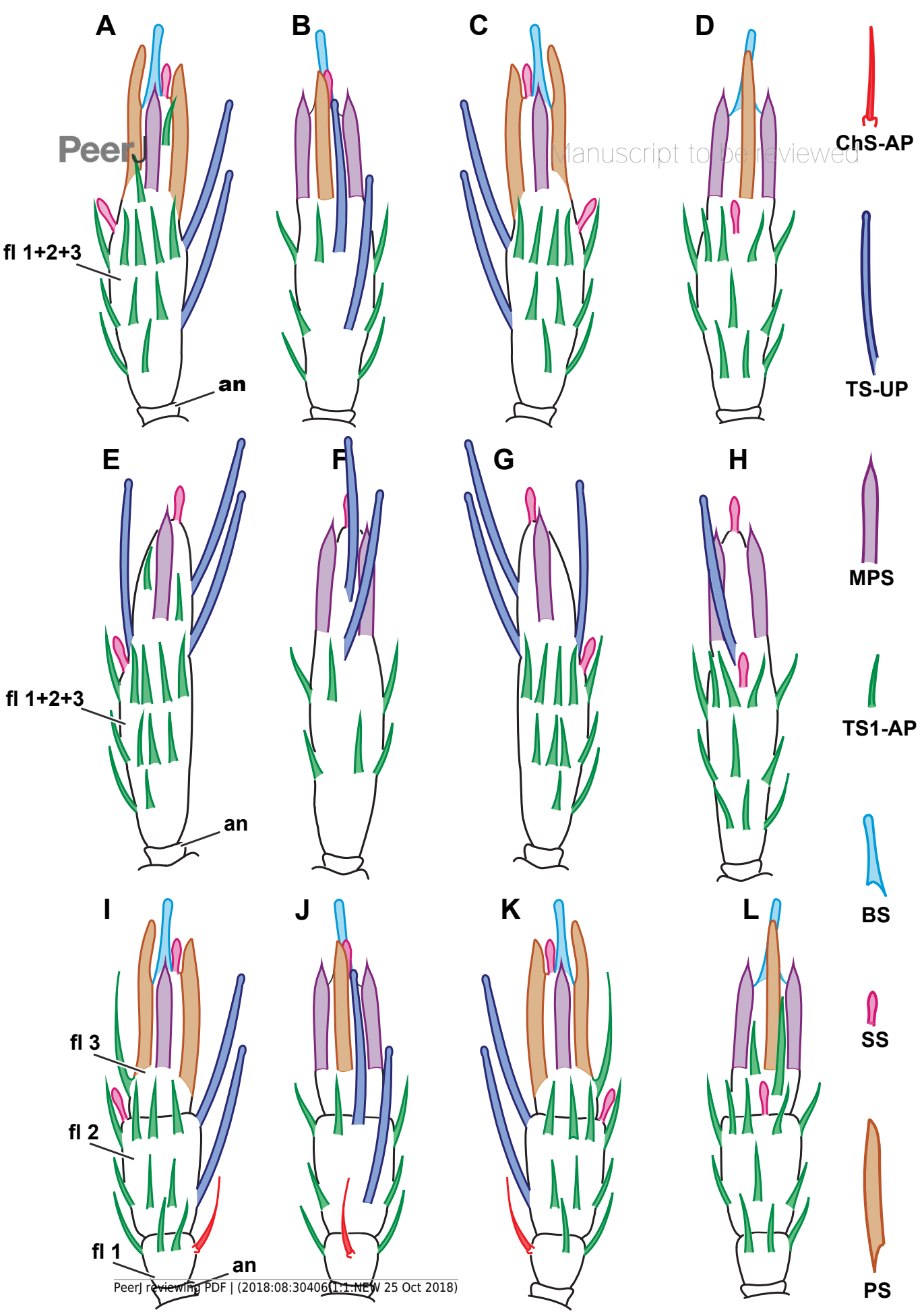


Figure 7 (on next page)

Changes in number of antennal sensilla and number of types of antennal sensilla in parasitoid wasps.

(A) The effect of miniaturization on the number of antennal sensilla. Data on Chalcidoidea and Braconidae species are included. For references, see Table S4. (B) Number of antennal sensilla types as a function of body length. Data on Chalcidoidea and Braconidae species are included. For references, see Table S4. Trendlines representing correlated variables $(p<$ $0.01)$ with the slopes of SMA and OLS regressions significantly different from $0(p<0.01)$ are marked with three asterisks (***); for slope values and $\mathrm{R}^{2}$ see Table 2 . 


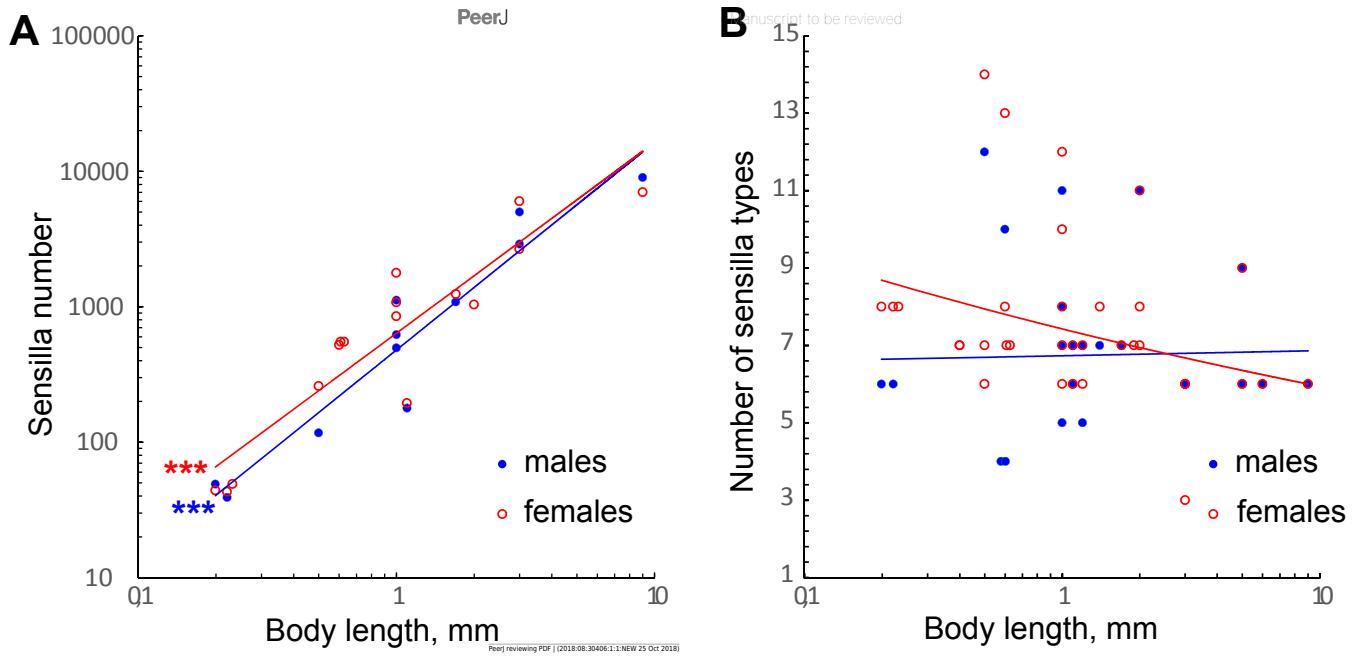




\section{Figure 8 (on next page)}

Size changes of three antennal sensilla types, mechanoreceptive ChS-AP, chemoreceptive MPS, and proprioreceptive TS2-AP in parasitoid wasps.

(A) Sensillum length as a function of body length. (B) Sensillum diameter as a function of body length. Data on Chalcidoidea, Scelionidae and Braconidae species are included. For references, see Table S4. Trendlines representing correlated variables with the slopes of SMA and OLS regressions significantly different from zero are marked with three asterisks ( $* * *)$ for $p<0.01$ and two asterisks (**) for $0.01 \leq p<0.05$. Trendlines for which only OLS demonstrated correlation between variables and significant difference of slope from 0 are marked with one asterisk $(*)$ for $0.01 \leq p<0.05$ (for slope values and $R^{2}$ see Table 2 ). 


\section{Table $\mathbf{1}$ (on next page)}

Megaphragma amalphitanum, M. mymaripenne and $M$. caribea numbers per antenna and sizes of antennal sensilla (mean $\pm s d$ ), measurements are given in $\mu \mathrm{m}$. For additional details, see Table S3. 


\begin{tabular}{|c|c|c|c|c|c|c|}
\hline \multirow{2}{*}{$\begin{array}{l}\text { Sensilla } \\
\text { type }\end{array}$} & \multirow[t]{2}{*}{ Parameter } & \multicolumn{2}{|c|}{$\begin{array}{l}\text { Megaphragma } \\
\text { amalphitanum }\end{array}$} & \multirow{2}{*}{$\begin{array}{c}M . \\
\text { mymaripenne } \\
\text { Female }\end{array}$} & \multicolumn{2}{|c|}{ M. caribea } \\
\hline & & Female & Male & & Female & Male \\
\hline \multirow{3}{*}{ ChS-AP } & Number & 9 & 10 & 9 & 8 & 8 \\
\hline & Length & $11.5 \pm 2.62$ & $9.89 \pm 2.88$ & $14.2 \pm 2.03$ & $8.04 \pm 1.49$ & $6.28 \pm 0.99$ \\
\hline & Diameter & $0.9 \pm 0.16$ & $0.71 \pm 0.11$ & $1.3 \pm 2.68$ & $0.75 \pm 0.12$ & $0.67 \pm 0.13$ \\
\hline \multirow{3}{*}{ TS1-AP } & Number & 17 & 14 & 22 & 18 & 25 \\
\hline & Length & $12.7 \pm 5.42$ & $7.63 \pm 1.59$ & $13.68 \pm 4.52$ & $8.41 \pm 3.54$ & $5.16 \pm 1.29$ \\
\hline & Diameter & $0.82 \pm 0.14$ & $0.65 \pm 0.09$ & $0.85 \pm 0.14$ & $0.72 \pm 0.13$ & $0.62 \pm 0.12$ \\
\hline \multirow{3}{*}{ TS-UP } & Number & 2 & 3 & 2 & 2 & 3 \\
\hline & Length & $37.1 \pm 5.59$ & $33.6 \pm 4.46$ & $29.93 \pm 4.78$ & $33.03 \pm 5.97$ & $20.42 \pm 2.87$ \\
\hline & Diameter & $1.36 \pm 0.23$ & $1.34 \pm 0.16$ & $1.36 \pm 0.19$ & $1.19 \pm 0.12$ & $1.28 \pm 0.2$ \\
\hline \multirow{3}{*}{$\mathrm{SS}$} & Number & & & & & \\
\hline & Length & $7 \pm 0.72$ & $5.05 \pm 0.48$ & $5.78 \pm 1.48$ & $4.78 \pm 0.83$ & $4.58 \pm 1.2$ \\
\hline & Diameter & $0.93 \pm 0.11$ & $0.76 \pm 0.09$ & $0.86 \pm 0.2$ & $0.99 \pm 0.11$ & $1 \pm 0.15$ \\
\hline \multirow{3}{*}{ TS2-AP } & Number & 9 & 9 & 9 & 9 & 9 \\
\hline & Length & $0.88 \pm 0.22$ & $1.03 \pm 0.36$ & $0.93 \pm 0.24$ & $0.89 \pm 0.21$ & $0.97 \pm 0.23$ \\
\hline & Diameter & $0.55 \pm 0.14$ & $0.53 \pm 0.12$ & $0.51 \pm 0.07$ & $0.57 \pm 0.03$ & $0.61 \pm 0.27$ \\
\hline \multirow{3}{*}{ BS } & Number & 1 & - & 1 & 1 & - \\
\hline & Length & $17.1 \pm 2.04$ & - & $14.8 \pm 2.19$ & $11.77 \pm 2$ & - \\
\hline & Diameter & $1.96 \pm 0.19$ & - & $1.85 \pm 0.29$ & $1.53 \pm 0.21$ & - \\
\hline \multirow{4}{*}{ PS } & Number & 2 & - & 2 & 2 & - \\
\hline & Length & $39.9 \pm 4.15$ & - & $29.77 \pm 3.84$ & 43324 & - \\
\hline & Diameter & $2.48 \pm 0.6$ & - & $2.22 \pm 0.51$ & $1.87 \pm 0.19$ & - \\
\hline & Tip length & $11.7 \pm 4.32$ & - & $9.17 \pm 4.08$ & $6.83 \pm 1.86$ & - \\
\hline \multirow{4}{*}{ MPS } & Number & 2 & 2 & 2 & 2 & 2 \\
\hline & Length & $37.3 \pm 3.58$ & $21.9 \pm 5.61$ & $31.94 \pm 3.57$ & $25.74 \pm 2.29$ & $21.55 \pm 2.5$ \\
\hline & Diameter & $2.62 \pm 0.27$ & $1.82 \pm 0.38$ & $2.45 \pm 0.5$ & $2.3 \pm 0.15$ & $1.73 \pm 0.35$ \\
\hline & Tip length & $3.69 \pm 1.36$ & $3.76 \pm 4.51$ & $6.66 \pm 4.77$ & $1.8 \pm 1.16$ & $21.55 \pm 2.5$ \\
\hline
\end{tabular}




\section{Table 2 (on next page)}

Slope values and $R^{2}$ of regression analyses performed on the data on the number of antennal sensilla, number of antennal sensilla types, and antennal sensilla sizes in parasitoid wasps.

***, variables are correlated, slope is significantly different from 0 with $p<0.01 ; *$, variables are correlated, slope is significantly different from 0 with $0.01 \leq p<0.05$. 


\begin{tabular}{|l|c|c|c|c|}
\hline \multicolumn{1}{|c|}{ Dependent variable/independent variable } & \multicolumn{2}{c|}{ SMA } & \multicolumn{2}{c|}{ OLS } \\
\cline { 2 - 5 } & Slope & $\mathbf{R}^{\mathbf{2}}$ & Slope & $\mathbf{R}^{\mathbf{2}}$ \\
\hline Number of antennal sensilla/body length, males & $1.60 * * *$ & 0.91 & $1.53 * * *$ & 0.91 \\
\hline Number of antennal sensilla/body length, females & $1.53 * * *$ & 0.84 & $1.4 * * *$ & 0.84 \\
\hline $\begin{array}{l}\text { Number of antennal sensilla types/body length, } \\
\text { males }\end{array}$ & 0.30 & $\begin{array}{c}0.000 \\
7\end{array}$ & 0.008 & 0.0007 \\
\hline $\begin{array}{l}\text { Number of antennal sensilla types/body length, } \\
\text { females }\end{array}$ & 0.24 & 0.10 & 0.08 & 0.11 \\
\hline ChS-AP length/body length, females & & & & \\
\hline ChS-AP diameter/body length & 0.45 & 0.007 & 0.037 & 0.007 \\
\hline MPS length/body length & 0.42 & 0.35 & $0.25 *$ & 0.19 \\
\hline MPS diameter/body length & 0.76 & 0.36 & $0.39 *$ & 0.36 \\
\hline TS2-AP length/body length & $0.94 * * *$ & 0.56 & 0.39 & 0.11 \\
\hline TS2-AP diameter/body length & $0.58 *$ & 0.45 & $0.39 *$ & 0.45 \\
\hline
\end{tabular}
1 